\title{
Cerebral blood flow velocity variability after cardiovascular support in premature babies
}

\author{
J M RENNIE
}

Department of Paediatrics, University of Cambridge

SUMMARY The variability of cerebral blood flow velocity was measured in 20 very low birthweight infants. The area under the curve of the Doppler frequency spectrum was used and was obtained from the anterior cerebral artery in the infants before and after infusions of plasma or dopamine. Both interventions significantly reduced the variability without a demonstrable effect on cardiac output, heart rate, or cerebral blood flow velocity. The reduction was from a median of $13 \%$ to $5 \%$ after plasma and from $13 \%$ to $4 \%$ after dopamine. The effect was probably due to an increase in circulating blood volume. It is proposed that appreciable variations in systolic blood pressure occurring in phase with respiration indicate a low central venous pressure in infants, as in adults and animals. The variations could be transmitted to the cerebral circulation in the absence of autoregulation, and their detection in either the aorta or a cerebral artery may prove a useful index of hypovolaemia.

The theory that most instances of neonatal brain injury occur after alterations in cerebral blood flow remains unchallenged. Evidence continues to accumulate showing that the cerebral circulation of some preterm babies is 'pressure passive', easily transmitting variations of systemic blood pressure (F Cowan, M Eriksen, D Wertheim. Assessment of cerebral autoregulation in the preterm infant. Presented at the Neonatal Society, London, 1988). ${ }^{1}$ High peaks in systemic blood pressure, low mean arterial pressure, and high beat to beat variability in systemic and cerebral blood pressure have all been suggested as risk factors preceding cerebral abnormalities. ${ }^{2-4}$ Ultrasound can accurately diagnose many neonatal intracranial lesions and the information used to predict later neurodevelopmental handicap with improving sensitivity and specificity. ${ }^{5}$ In addition to producing a real time image ultrasound can be used with the application of the Doppler principle to obtain information regarding the velocity of blood flow in vessels. While repeated accurate quantitation of cerebral blood flow remains impossible, work in which the limitations of the method have been understood has led to some useful observations regarding the cerebral circulation. One example is a high variability in some babies, the origins of which probably lie in cardiovascular changes secondary to respiration. ${ }^{4}$

Small changes in left ventricular stroke volume occur throughout the normal respiratory cycle, with a slight decrease in systolic blood pressure during the early phase of inspiration. ${ }^{6}$ This finding when exaggerated is well known as pulsus paradoxus. Reversed pulsus paradoxus, with a rise in systemic blood pressure during positive pressure inflation, ${ }^{7}$ is thought to result from an increase in left ventricular filling due to blood being 'squeezed' out of the lungs by the ventilator pressure. ${ }^{8}$ Changes from respiration induced alterations in intrathoracic pressure probably make a major contribution to the blood pressure and cerebral blood flow velocity perturbations. The changes will be more variable in awake ventilated infants who may interact with positive pressure ventilation in several ways. ${ }^{9}$ It is not surprising, therefore, that variability of cerebral blood flow velocity can be reduced by temporary cessation of artificial ventilation, ${ }^{10}$ paralysis, ${ }^{11}$ or inducing the baby to breathe in synchrony with his ventilator. ${ }^{12}$ Spectral analysis of blood pressure and variations in cerebral blood flow velocity has shown a low frequency component with a periodicity identical to that of the respiratory cycle. ${ }^{3}$

Blood pressure variation during positive pressure respiration has been studied in ventilated adults and in animals; in both the variations are a sensitive indicator of hypovolaemia. ${ }^{14}$ In order to investigate this possibility in preterm infants, cerebral blood flow velocity variability was measured in preterm babies before and after infusions of plasma and dopamine. 


\section{Subjects and methods}

Twenty babies of median birth weight $1230 \mathrm{~g}$ (range from 713 to 1900) and median gestational age 29 weeks (range 24 to 32 ) who were treated with plasma $(n=11)$ or dopamine $(n=9)$ in the first 24 hours of life were studied. The protocol was approved by the local ethical committee, and the work carried out in the Cambridge neonatal intensive care unit. All the babies were ventilated for hyaline membrane disease, and the reason for treatment was usually a blood pressure below that usual for their weight, ${ }^{15}$ although some babies received plasma for underperfusion of one or both lower limbs after insertion of an umbilical artery catheter without a low mean arterial pressure. Babies with low blood pressure were treated with plasma initially, and if this failed to improve the mean systolic pressure to about $40 \mathrm{~mm} \mathrm{Hg}$ dopamine was instituted. No baby was studied twice and those in the dopamine group who received dopamine after plasma were studied at least one hour after colloid infusion.

Measurements of cerebral blood flow velocity were made from the anterior cerebral artery via the fontanelle using Duplex Doppler ultrasound (ATL Mk600). The Doppler shifted spectrum was collected by an Apple IIe microcomputer in order to calculate the time averaged mean velocity from 3.5 seconds of information. ${ }^{16}$ The same software was used to collect spectra and calculate velocity from the Doppler shift obtained from blood flowing in the ascending aorta by using the real time image obtained via a suprasternal approach. ${ }^{17}$ The diameter of the aorta was measured in a parasternal long axis view using $M$ mode echocardiography enabling calculation of the cardiac output from the relation: flow $=$ velocity $\times$ area.

Variability of cerebral blood flow was quantified by obtaining a paper record of the Fourier transform of the Doppler spectra and tracing the area under the curve for each of 10 consecutive cardiac cycles with computer assisted planimetry. Variability was then expressed as the coefficient of variation for the area, that is the standard deviation divided by the mean expressed as a percentage.

Estimates of cardiac output, anterior cerebral artery velocity and variability were made before and 30 minutes after either giving $10 \mathrm{ml} / \mathrm{kg}$ of plasma over 30 minutes or the start of a dopamine infusion at a dose of $10 \mu \mathrm{g} / \mathrm{kg} /$ minute. The observations described were made and the data stored on disc or on paper traces for completion of analysis at a later time after coding to reduce bias. Records of the blood pressure and heart rate measured with oscillometry (Dinamap) were made, and the ventilator settings were not changed. No babies were paralysed, but a detailed analysis of the infant's interaction with the ventilator was not attempted in this study.

Statistical analysis used the Wilcoxon signed rank test and the sign test for paired observations.

\section{Results}

The coefficient of variation in cerebral blood flow velocity fell significantly after treatment with dopamine and after plasma: from a median of $13 \%$ to $4 \%$ after dopamine $(p=0 \cdot 01$, Wilcoxon $)$ and from a median of $13 \%$ to $5 \%$ after plasma (fig 1 ). Dopamine but not plasma was followed by a significant increase in systolic blood pressure $(p=0.01$ dopamine, $p=0.36$ plasma, fig 2 ). Recordings from one
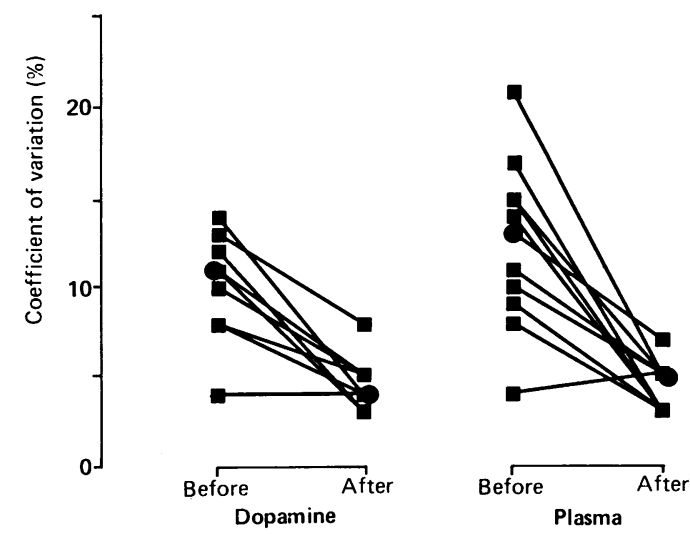

Fig 1 Coefficient of variation of cerebral blood flow velocity before and after dopamine and plasma. Median values shown as circles.

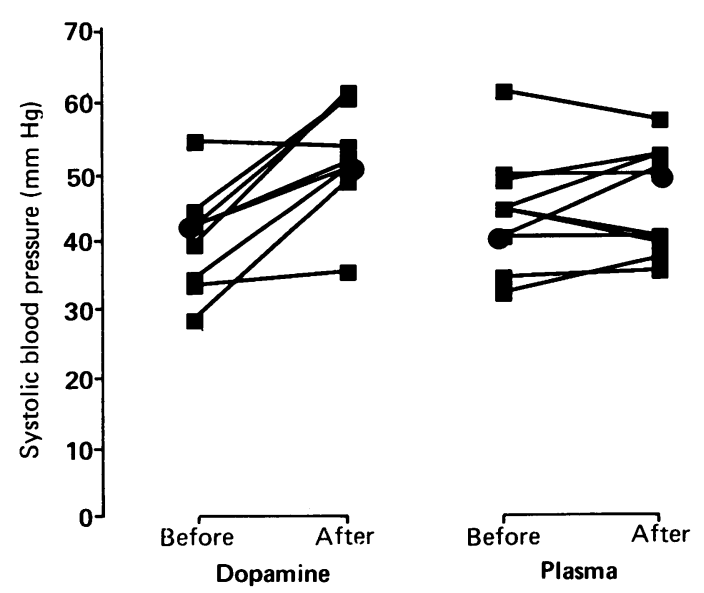

Fig 2 Sytolic blood pressure ( $\mathrm{mm} \mathrm{Hg}$ ) before and after dopamine and plasma. Median values shown as circles. 


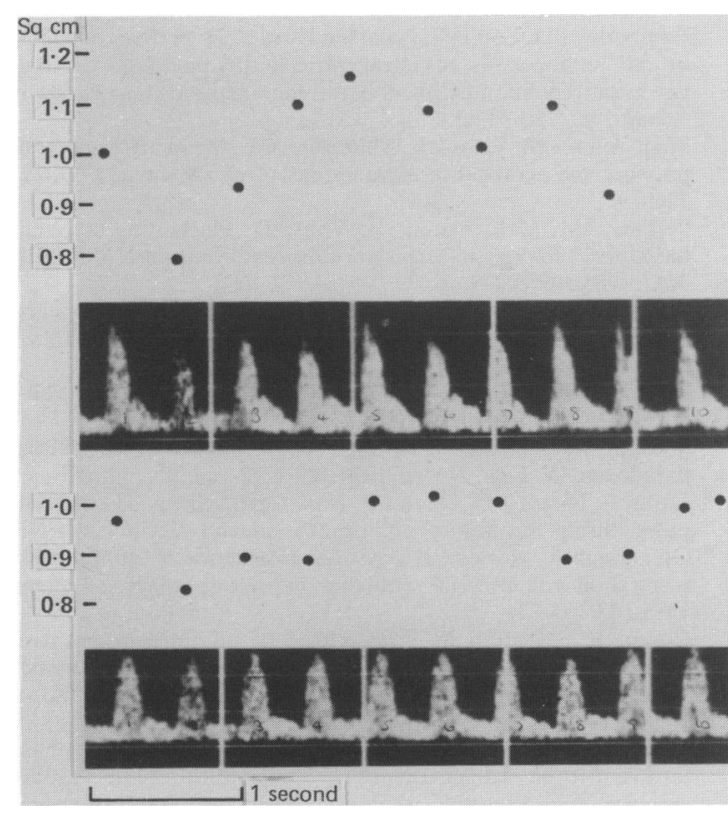

Fig 3 Spectral analysis of Doppler shift in one baby before (above) and after (below) the commencement of a dopamine infusion.

Table Cardiac output and cerebral blood flow velocity before and after dopamine and plasma. Results are medians (interquartile ranges)

\begin{tabular}{lll}
\hline & $\begin{array}{l}\text { Cardiac output } \\
\text { (ml/kg/minute) }\end{array}$ & $\begin{array}{l}\text { Cerebral blood } \\
\text { flow velocity } \\
(\mathrm{cm} / \text { second })\end{array}$ \\
\hline $\begin{array}{l}\text { Dopamine: } \\
\text { Before }\end{array}$ & $149(133-263)$ & $5 \cdot 6(3 \cdot 2-8 \cdot 0)$ \\
$\begin{array}{c}\text { After } \\
\begin{array}{l}\text { Plasma: } \\
\text { Before }\end{array}\end{array}$ & $154(126-207)$ & $5 \cdot 5(4 \cdot 0-7 \cdot 8)$ \\
After & $173(134-228)$ & $3 \cdot 8(2 \cdot 3-9 \cdot 4)$ \\
\hline
\end{tabular}

baby are shown in fig 3 , with the spectral analysis together with the area under the curve for 10 cardiac cycles before and after dopamine. There is a sinusoidal variation corresponding to ventilation which is damped but not abolished by dopamine.

The table shows values for cardiac output and cerebral blood flow velocity. There was no effect on these indices or the heart rate after either form of treatment.

\section{Discussion}

These results show that the beat to beat variability of cerebral blood flow velocity was reduced by the administration of plasma and dopamine. Fluctuations seen in the cerebral circulation occurring with positive pressure ventilation are well recognised ${ }^{18}$ and reflect the changes in pressure and velocity in the aorta. ${ }^{4}$ Fluctuations during spontaneous respiration also occur, ${ }^{13}$ and short term alterations in the Pourcelot index of cerebral blood flow velocity at times of fetal breathing greater than those during fetal apnoea have been reported. ${ }^{19}$ Fluctuations in systolic blood pressure were more exaggerated in a group of ventilated dogs hypotensive after hypovolaemia than those rendered hypotensive after vasodilator treatment. ${ }^{20}$ The effects of plasma in this study were probably due to an increase in circulating blood volume, although it was not possible to measure this directly. These results could provide one explanation for the result of the study of Beverley et al using fresh frozen plasma in the protection of periventricular haemorrhage. ${ }^{21}$ The provision of coagulation factors by the administration of $10 \mathrm{ml} / \mathrm{kg}$ of plasma did not alter in the babies, and were unlikely to have accounted for the beneficial effect observed. If the interpretation of the results presented here is correct and blood pressure fluctuations in the newborn are exaggerated during hypovolaemic hypotension, then the relation between fluctuating cerebral blood flow velocity and periventricular haemorrhage ${ }^{422}$ occurred probably because low circulating blood volume was a common factor in both periventricular haemorrhage and fluctuating cerebral blood flow rather than fluctuating cerebral blood flow causing capillary rupture.

Dopamine could have effectively increased circulating blood volume by increasing systemic vascular resistance and central venous pressure. Babies who received dopamine had invariably already received plasma about an hour previously and were started on an inotrope because of failure to respond, hence the lower systemic pressure seen before treatment in fig 2. The amount of plasma used probably had an insignificant effect on circulating blood volume at this time, however, and an additional explanation for the effect of dopamine has to be sought. The agent is both a direct and indirect beta adrenergic receptor agonist with some alpha adrenergic receptor agonist properties. Several groups have examined the effects in children, in whom an increase or no alteration in central venous pressure and systolic blood pressure occurred. ${ }^{23}$ The alpha adrenergic effects predominate at high doses with an increase in systemic vascular resistance. ${ }^{24} \mathrm{An}$ increase in cardiac output without an increase in heart rate was seen by Padbury $e t a l,{ }^{25}$ and although the neonatal myocardium is known to have poor compliance this and the observation in the current study 
of an increase in systolic blood pressure without an increase in heart rate show that the myocardial response is not limited to rate alone. Work showing an improvement in shortening fraction after dopamine treatment also suggests that the concept that the neonatal heart is at the limit of the FrankStarling curve may be too simplistic. ${ }^{26}$ These results fail to show an increase in cardiac output with the method used despite an increase in systolic blood pressure. Previous studies showing an increase in cardiac output after dopamine have included babies who were shocked before administration with a cardiac output of the order of $100 \mathrm{ml} / \mathrm{kg} /$ minute, ${ }^{27}$ well below the normal for the newborn. ${ }^{28}$ Our threshold for using dopamine is low and the babies reported here entered the study with a cardiac output in the normal range. This or methodological problems could have explained the absence of an increase. The method described has been compared with thermodilution in an animal model, giving correlations of between 0.48 and 0.88 , with $95 \%$ confidence intervals for the difference in methods ranging from 30 to $40 \mathrm{ml}$ (JM Rennie, RD Barnes. Comparison of cardiac output estimated with Doppler ultrasound and thermodilution in rabbits. Presented at Neonatal Doppler meeting, Leicester, 1987). A Doppler method for cardiac output compared well with a method based on the Fick principle at cardiac catheterisation in children. ${ }^{17}$

The effects of mechanical ventilation on the circulation in sick newborn babies may be more complex than we suspect and remain to be fully explored. The results of this study show a reduction in variability of cerebral blood flow velocity after cardiovascular support and support the observations made in animals that an exaggeration of the variability in systolic blood pressure occurring with ventilation indicates hypovolaemia. Blood pressure is often monitored continuously in premature babies and further analysis of the signal may show a variability which relates to central venous pressure in this way. This could prove of clinical value in neonatal intensive care units where measurement of central venous pressure is difficult.

Thanks are due to Dr Colin Morley (paediatrics) and Dr John Klink (anaesthetics) for useful discussion during this work. Financial support was obtained from Children Nationwide, the East Anglian Regional Area Health Authority, and the Trustees of

\section{References}

1 Lou HC, Lassen NA, Friis-Hansen B. Impaired autoregulation of cerebral blood flow in the distressed newborn infant. J Pediatr 1979;94:118-21.
${ }^{2}$ Wimberley PD, Lou HC, Pedersen $\mathrm{H}$, et al. Hypertensive peaks in the pathogenesis of intraventricular haemorrhage in the newborn. Abolition by phenobarbitone sedation. Acta Paediatr Scand 1982;71:537-42.

${ }^{3}$ Miall-Allen VM, Vries LS, Whitelaw AGL. Mean arterial blood pressure and neonatal cerebral lesions. Arch Dis Child 1987;62: 1068-9.

4 Perlman JM, McMenamin JB, Volpe JJ. Fluctuating cerebral blood flow velocity in respiratory distress syndrome. $N$ Engl J Med 1983;309:204-9.

5 Cooke RWI. Early and late cranial ultrasonographic appearances and outcome in very low birthweight infants. Arch Dis Child 1987;62:931-7.

${ }^{6}$ Guyton AC. Textbook of medical physiology. 5th ed. Philadelphia: WB Saunders, 1976:242.

7 Masumi RA, Mason DT, Vera Z, et al. Reversed pulsus paradoxus. N Engl J Med 1973;289:1272-5.

8 Jardin F, Farcot J-C, Gueret P, et al. Cyclic changes in arterial pulse during respiratory support. Circulation 1983;68:266-74.

9 Greenough A, Morley CJ, Davis JA. Interaction of spontaneous respiration with artificial ventilation in preterm babies. $J$ Pediatr 1983;103:769-73.

${ }^{10}$ Cowan F, Thoresen M. The effects of intermittent positive pressure ventilation on cerebral arterial and venous blood velocities in the newborn infant. Acta Paediatr Scand 1987;76: $239-47$.

11 Perlman JM, Goodman S, Kreusser KL, Volpe JJ. Reduction in intraventricular haemorrhage by elimination of fluctuating cerebral blood flow velocity in preterm infants with respiratory distress syndrome. $N$ Engl J Med 1985;312:1353-7.

12 Rennie JM, South M, Morley CJ. Cerebral blood flow velocity variability in infants receiving assisted ventilation. Arch Dis Child 1987;62:1247-51.

13 Bignall S, Bailey PC, Rivers RPA, Lissauer TJ. Quantification of cardiovascular instability in premature infants using spectral analysis of waveforms. Pediatr Res 1988;23:398-401.

14 Perel A, Pizov R, Cotev S. The systolic blood pressure variation is a sensitive indicator of hypovolaemia in ventilated dogs subjected to graded haemorrhage. Anaesthesiology 1987;67: 498-502.

15 Kitterman JA, Phibbs RH, Tooley WH. Aortic blood pressure in normal newborn infants during the first 12 hours. Pediatrics 1969;44:959-68.

16 Drayton MR, Skidmore R. Ductus arteriosus blood flow during the first 48 hours. Arch Dis Child 1987;62:1030-4.

17 Alverson DC, Eldridge M, Dillon T, et al. Noninvasive pulsed Doppler determination of cardiac output. J Pediatr 1982;101: 46-50.

${ }^{18}$ Cowan F, Thoresen M. The effects of intermittent positive pressure ventilation on cerebral arterial and venous blood velocities in the newborn infant. Acta Paediatr Scand 1987;76: 239-47.

19 Wladimiroff JW, van Bel F. Fetal and neonatal cerebral blood flow. Semin Perinatol 1987;11:335-46.

20 Pizov R, Ya'ari Y, Perel A. Systolic pressure variation is greater during haemorrhage than during sodium nitroprusside-induced hypotension in ventilated dogs. Anesth Analg 1988;67:170-4.

21 Beverley DW, Pitts-Tucker TJ, Congdon PJ, et al. Prevention of IVH by fresh frozen plasma. Arch Dis Child 1985;60:710-3.

22 Van Bel F, van de Bor M, Stijrien T, et al. Aetiological role of cerebral blood flow alterations in development and extension of peri- intraventricular haemorrhage. Dev Med Child Neurol 1987;29:601-14.

${ }^{23}$ Driscoll DJ, Gilette PC, McNamara DG. The use of dopamine in children. $J$ Pediatr 1978;92:309-14.

${ }^{24}$ Driscoll DJ. The use of inotropic and chronotropic agents in neonates. Clin Pediatr 1987;14:931-48.

25 Padbury JE, Agata Y, Baylen BG, et al. Dopamine pharmacokinetics in critically ill newborn infants. J Pediatr 1986;110: 293-8. 
26 Walther FJ, Siassi B, Ramadan NA, Wu P Y-C. Cardiac output in newborn infants with transient myocardial dysfunction. $J$ Pediatr 1985;107:781-5.

27 DiSiessa TG, Leitner M, Ti CC, et al. The cardiovascular effects of dopamine in the severely asphyxiated neonate. $J$ Pediatr 1981;99:772-6.

28 Walther FJ, Siassi B, Ramadan NA, et al. Pulsed Doppler determinations of cardiac output in neonates: normal standards for clinical use. Pediatrics 1985;76:829-33.

Correspondence and requests for reprints to Dr JM Rennie, Department of Paediatrics, Level E8, New Addenbrooke's Hospital, Hill's Road, Cambridge CB2 $2 \mathrm{QQ}$.

Accepted 24 November 1988 